\section{JURNAL EKONOMI EFEKTIF}

ISSN : $2622-8882$, E-ISSN : 2622-9935

Jurnal Ekonomi Efektif, Vol. 4, No. 2, Januari 2022 @Prodi Manajemen Fakultas Ekonomi

Universitas Pamulang

\title{
PENGARUH KEGIATAN PROMOSI TERHADAP KEPUTUSAN PEMBELIAN PRODUK KACANG MAYASI PADA PT MANOHARA ASRI DI JAKARTA
}

\author{
Muhamad Cikdan ${ }^{1}$, Sewaka $^{2 *}$ \\ Universitas Pamulang, Tangerang Selatan, Banten, Indonesia \\ cikdanmuhamad@gmail.com ${ }^{1}, \underline{\text { dosen00120@unpam.ac.id }{ }^{2 *}}$
}

Manuskrip: November -2021; Ditinjau: November: -2021; Diterima: Desember-2021; Online: Januari -2022; Diterbitkan: Januari-2022

\begin{abstract}
ABSTRAK
Penelitian ini bertujuan untuk mengetahui pengaruh kegiatan promosi terhadap keputusan pembelian produk kacang mayasi pada PT. Manohara Asri di Jakarta. Metode yang digunakan adalah explanatory research dengan sampel sebanyak 100 responden. Teknik analisis menggunakan analisis statistik dengan pengujian regresi, korelasi, determinasi dan uji hipotesis. Hasil penelitian ini variabel kegiatan promosi diperoleh nilai rata-rata skor sebesar 3,422 dengan kriteria baik. Variabel keputusan pembelian diperoleh nilai rata-rata skor sebesar 3,836 dengan kriteria baik. Kegiatan promosi berpengaruh positif dan signifikan terhadap keputusan pembelian dengan nilai persamaan regresi $\mathrm{Y}=7,748+0,895 \mathrm{X}$, dan nilai koefisien korelasi 0,790 atau memiliki tingkat hubungan yang kuat dengan nilai determinasi $62,5 \%$. Uji hipotesis diperoleh signifikansi $0,000<0,05$.
\end{abstract}

\section{Kata Kunci: Kegiatan Promosi, Keputusan Pembelian}

\section{ABSTRACT}

This study aims to determine the effect of promotional activities on purchasing decisions of mayasi peanut products at PT. Manohara Asri in Jakarta. The method used is explanatory research with a sample of 100 respondents. The analysis technique uses statistical analysis with regression, correlation, determination and hypothesis testing. The results of this research variable promotion activities obtained an average score of 3,422 with good criteria. Purchasing decision variables obtained an average score of 3,836 with good criteria. Promotional activities have a positive and significant effect on purchasing decisions with a regression equation value of $Y=7.748+0.895 X$, and a correlation coefficient value of 0.790 or has a strong relationship with a determination value of $62.5 \%$. Hypothesis testing obtained a significance of $0.000<0.05$.

Keywords: Promotion Activities, Purchase Decision 


\section{PENDAHULUAN}

\section{A. Latar Belakang}

Perkembangan dan kemajuan industri, salah satunya dapat kita lihat dengan adanya perkembangan dunia usaha yang semakin pesat. Hal ini dapat terlihat dengan munculnya industri barang dan jasa. Kemajuan sektor industri yang pesat menimbulkan tingkat persaingan usaha yang ketat.

Peningkatan taraf hidup dan gaya hidup masyarakat yang sangat beragam sekarang ini, membuat perusahaan harus dapat menciptakan produk yang kreatif serta inovatif dan mengikuti perkembangan mode saat ini, selain itu tentunya perusahaan harus melakukan kegiatan promosi untuk memperkenalkan dan memasarkan produk tersebut.

Dalam usaha menentukan langkah-langkah maju agar sesuai dengan tujuan perusahaan yaitu untuk memperoleh keuntungan semaksimal mungkin dengan potensi dan kemampuan yang maksimal, salah satu yang harus dilakukan untuk mencapai tujuan tersebut adalah dengan melalukan kegiatan pemasaran. Pemasaran merupakan salah satu bidang yang harus diperhatikan demi keberhasilan perusahaan di samping kegiatan bidang lainnya seperti produksi, personalia dan keuangan (budgeting).

Dalam bidang pemasaran berbagai masalah timbul selain persaingan juga berkembangnya keanekaragaman produk, meningkatnya selera konsumen, dan adanya produk baru yang dihasilkan, Untuk itu perusahaan dituntut untuk dapat menghadapi dan menyelesaikan berbagai masalah yang ada. Dalam menghadapi masalah yang datang dari berbagai arah perusahaan harus dapat meningkatkan efektivitas seluruh pengelolaan perusahaaan dalam menangani pemasaran produk. Kondisi seperti inilah yang pada akhirnya menyebabkan para pelaku usaha semakin gencar berusaha untuk mencari solusi maupun program bisnis yang dapat meningkatkan daya saing perusahaan didalam bisnisnya.

Namun demikian, meskipun perusahaan telah berusaha bersaing dan memberikan yang terbaik untuk konsumen belum tentu dapat menjamin akan berhasilnya usaha pencapaian tujuan perusahaan, karena tiap konsumen memiliki selera dan keinginan yang berbeda-beda. Maka dari itu setiap perusahaan memiliki strategi pemasaran yang berbeda-beda, yang merupakan strategi terbaik disetiap perusahaan. Dengan melakukan hal tersebut perusahaan dapat menarik minat, ketertarikan, dan menggugah masyarakat untuk membeli produk barang atau jasa yang dihasilkan perusahaan tersebut. PT. Manohara Asri merupakan suatu perusahaan swasta yang bergerak di bidang usaha makanan dengan mengutamakan kualitas yang terbaik bagi produknya. Beragam jenis produk makanan dihasilkan oleh perusahaan. Salah satunya adalah produk Kacang, yang merupakan produk makanan ringan.

Permasalahan yang terjadi pada PT Manohora Asri (Kacang Mayasi) yaitu Kurang efektifnya kegiatan-kegiatan promosi yang dilakukan PT manohara asri, Keputusan pembelian konsumen produk kacang mayasi masih rendah dan Kegiatan promosi masih tidak ada dampak terhadap minat beli konsumen.

Untuk itu diharapkan kegiatan-kegiatan promosi yang dilakukan dapat mengenai sasaran dengan tepat, guna memberikan informasi mengenai produk kacang mayasi, promosi dimaksudkan untuk menarik minat beli pelanggan, antara lain dengan memberikan informasi selengkapnya kepada pelanggan akan suatu produk yang dipasarkan, jika kegiatan promosi terlaksana dengan baik maka pelanggan akan tertarik dan akan membeli produk tersebut.

Maka dari itu promosi memegang penting dalam mencapai tujuan perusahaan terutama dalam mendapatkan keuntungan maksimal dengan biaya terkecil. Promosi 
merupakan kegiatan pokok yang dilakukan pengusaha untuk kelangsungan hidup perusahaan yang selanjutnya berkembang dan mencapai hasil penjualan yang diinginkan, sehingga dapat diartikan bahwa kepuasan konsumen merupakan suatu keadaan dimana keinginan dan harapan pelanggan dapat terpenuhi.

Kegiatan promosi dilakukan guna memberikan informasi kepada konsumen yang masih belum mengenal produk secara jelas, didukung dengan penyajian programprogram promosi lainnya yang berhubungan dengan produk yang dipasarkan, hal ini dapat mendorong keputusan pembelian konsumen akan suatu produk, keputusan pembelian konsumen diharapkan akan berubah dari yang sebelumnya tidak berminat untuk membeli menjadi berminat untuk membeli.

Slameto (2010:180) menyatakan bahwa "Minat adalah suatu rasa lebih suka dan rasa ketertarikan pada suatu hal atau aktivitas, tanpa ada yang menyuruh.”. Hal yang kontradiktif justru terjadi diperusahaan diantaranya kegiatan-kegiatan promosi yang dilakukan PT Manohara Asri dalam mempengaruhi keputusan pembelian konsumen masih sangat minim, keputusan pembelian konsumen cenderung berkurang sehingga mengurangi omset penjualan.

Hal ini dipengaruhi oleh kegiatan yang dilakukan contohnya menyelenggarakan program sosialisasi produk sebagai ajang memberikan informasi mengenai produk lama yang sudah ada dengan tujuan agar manfaat dari produk dapat digunakan dengan baik dan benar oleh pelanggan, selain itu untuk menarik keputusan pembelian pelanggan PT Manohara Asri juga menyelenggarakan acara-acara untuk memperkenalkan produk barunya, cara ini dimaksudkan untuk memberikan gambaran terhadap konsumen akan produk, dan agar lebih menarik perhatian konsumen, penyelenggaraan disarankan dapat menyediakan berbagai macam hadiah yang dapat menarik keputusan pembelian konsumen, dengan demikian penulis tertarik untuk mengadakan riset lebih lanjut, adapun judul penelitian yang penulis lakukan adalah "Pengaruh Kegiatan Pomosi Terhadap Keputusan Pembelian Konsumen Produk Kacang Mayasi PT Manohara Asri di Jakarta".

\section{B. Rumusan Masalah}

a. Bagaimana kegiatan promosi pada PT. Manohara Asri di Jakarta ?.

b. Bagaimana keputusan pembelian pada PT. Manohara Asri di Jakarta ?.

c. Adakah pengaruh antara kegiatan promosi terhadap keputusan pembelian pada PT. Manohara Asri di Jakarta?.

\section{Tujuan Penelitian}

a. Untuk mengetahui kondisi kegiatan promosi pada PT. Manohara Asri di Jakarta.

b. Untuk mengetahui kondisi keputusan pembelian pada PT. Manohara Asri di Jakarta.

c. Untuk mengetahui pengaruh kegiatan promosi terhadap keputusan pembelian pada PT. Manohara Asri di Jakarta.

\section{TINJAUAN PUSTAKA}

\section{Kegiatan Promosi}

Menurut Kotler dalam Tjiptono (2019) menyatakan bahwa "Kegiatan promosi adalah tingkat keunggulan yang diharapkan dan pengendalian atas tingkat keunggulan tersebut untuk memenuhi keinginan pelanggan".

\section{Keputusan Pembelian}

Menurut Kotler dan Amstrong (2019) berpendapat "perilaku konsumen merupakan sebuah pendekatan penyesuaian masalah yang terdiri dari lima tahap yang dilakukan 
konsumen. Kelima tahap tersebut adalah pengenalan masalah, pencarian informasi, evaluasi alternatif, keputusan pembelian, dan perilaku pasca pembelian”.

\section{METODE PENELITIAN}

\section{Populasi}

Yang dijadikan sebagai populasi dalam penelitian ini adalah responden yang berjumlah 100 responden PT. Manohara Asri di Jakarta

\section{Sampel}

Teknik pengambilan sampling dalam penelitian ini adalah sampel jenuh, dimana semua anggota populasi dijadikan sebagai sampel. Dengan demikian sampel dalam penelitian ini sampel yang digunakan berjumlah 100 responden.

\section{Jenis Penelitian}

Jenis penelitian yang dipakai adalah asosiatif, dimana tujuannya adalah untuk mengetahui atau mencari keterhubungan antara variabel independen terhadap variabel dependennya.

\section{Metode Analisis Data}

Dalam menganalisis data digunakan uji validitas, uji reliabilitas, analisis regresi linier sederhana, analisis koefisien korelasi, analisis koefisien determinasi dan pengujian hipotesis.

\section{HASIL PENELITIAN}

\section{Analisis Deskriptif}

Pada pengujian ini digunakan untuk mengetahui skor minimum dan maksimum skor tertinggi, ratting score dan standar deviasi dari masing-masing variabel. Adapun hasilnya sebagai berikut:

Tabel 1. Hasil Analisis Descriptive Statistics

Descriptive Statistics

\begin{tabular}{ll|r|r|r|r} 
& N & Minimum & Maximum & Mean & Std. Deviation \\
\hline Kegiatan Promosi (X) & 100 & 28 & 44 & 34.22 & 3.754 \\
\hline Keputusan Pembelian (Y) & 100 & 29 & 49 & 38.36 & 4.249 \\
\hline Valid N (listwise) & 100 & & & & \\
\hline
\end{tabular}

Kegiatan promosi diperoleh varians minimum sebesar 28 dan varians maximum 44 dengan ratting score sebesar 3,422 dengan standar deviasi 3,754. Skor ini termasuk pada rentang sakala 3,40-4,19 dengan kriteria baik atau setuju. Keputusan pembelian diperoleh varians minimum sebesar 29 dan varians maximum 49 dengan ratting score sebesar 3,836 dengan standar deviasi 4,249. Skor ini termasuk pada rentang sakala 3,40 $-4,19$ dengan kriteria baik atau setuju.

\section{Analisis Kuantitatif}

Pada analisis ini dimaksudkan untuk mengetahui pengaruh variabel independen terhadap variabel dependen. Adapun hasil pengujian sebagai berikut:

\section{a. Analisis Regresi Linier Sederhana}

Uji regresi ini dimaksudkan untuk mengetahui perubahan variabel dependen jika variabel independen mengalami perubahan. Adapun hasil pengujiannya sebagai berikut: 
Tabel 2. Hasil Pengujian Regresi Linier Sederhana Coefficients ${ }^{\mathbf{a}}$ Unstandardized Coefficients

\begin{tabular}{|c|c|c|c|c|c|}
\hline \multirow[b]{2}{*}{ Model } & \multicolumn{2}{|c|}{ Coefficients } & \multirow{2}{*}{$\begin{array}{l}\text { Coefficients } \\
\text { Beta }\end{array}$} & \multirow[b]{2}{*}{$\mathrm{t}$} & \multirow[b]{2}{*}{ Sig. } \\
\hline & $\mathrm{B}$ & Std. Error & & & \\
\hline $\begin{array}{ll}1 & \text { (Constant) }\end{array}$ & 7.748 & 2.411 & & 3.214 & .002 \\
\hline Kegiatan Promosi (X) & .895 & .070 & .790 & 12.774 & .000 \\
\hline
\end{tabular}

a. Dependent Variable: Keputusan Pembelian (Y)

Berdasarkan hasil pengujian pada tabel di atas, diperoleh persamaan regresi $\mathrm{Y}$ $=7,748+0,895 \mathrm{X}$. Dari persamaan tersebut dijelaskan sebagai berikut:

1) Konstanta sebesar 7,748 diartikan jika kegiatan promosi tidak ada, maka telah terdapat nilai keputusan pembelian sebesar 7,748 point.

2) Koefisien regresi kegiatan promosi sebesar 0,895 , angka ini positif artinya setiap ada peningkatan kegiatan promosi sebesar 0,895 point maka keputusan pembelian juga akan mengalami peningkatan sebesar 0,895 point.

\section{b. Analisis Koefisien Korelasi}

Analisis koefisien korelasi dimaksudkan untuk mengetahui tingkat kekuatan hubungan dari variabel independen terhadap variabel dependen. Adapun hasil pengujian sebagai berikut:

Tabel 3. Hasil Pengujian Koefisien Korelasi Kegiatan Promosi Terhadap Keputusan Pembelian.

\begin{tabular}{|c|c|c|c|}
\hline \multicolumn{4}{|c|}{ Correlations $^{\mathbf{b}}$} \\
\hline & & $\begin{array}{c}\text { Kegiatan } \\
\text { Promosi }(\mathrm{X})\end{array}$ & $\begin{array}{c}\text { Keputusan } \\
\text { Pembelian (Y) }\end{array}$ \\
\hline \multirow[t]{2}{*}{ Kegiatan Promosi (X) } & Pearson Correlation & 1 & $.790^{* *}$ \\
\hline & Sig. (2-tailed) & & .000 \\
\hline \multirow[t]{2}{*}{ Keputusan Pembelian (Y) } & Pearson Correlation & $.790^{* *}$ & 1 \\
\hline & Sig. (2-tailed) & .000 & \\
\hline
\end{tabular}

\section{c. Analisis Koefisien Determinasi}

Analisis koefisien determinasi dimaksudkan untuk mengetahui besarnya persentase pengaruh dari variabel independen terhadap variabel dependen. Adapun hasil pengujian sebagai berikut:

Tabel 4. Hasil Pengujian Koefisien Determinasi Kegiatan Promosi Terhadap Keputusan Pembelian.

\section{Model Summary}

\begin{tabular}{|c|c|c|c|c|}
\hline \\
\hline Model & $\mathrm{R}$ & R Square & $\begin{array}{l}\text { Adjusted R } \\
\text { Square }\end{array}$ & $\begin{array}{l}\text { Std. Error of the } \\
\text { Estimate }\end{array}$ \\
\hline 1 & $.790^{\mathrm{a}}$ & .625 & .621 & 2.616 \\
\hline
\end{tabular}

Berdasarkan hasil pengujian diperoleh nilai determinasi sebesar 0,625 artinya kegiatan promosi memiliki kontribusi pengaruh sebesar 62,5\% terhadap keputusan pembelian, sedangkan sisanya sebesar 37,5\% dipengaruhi oleh faktor lain yang tidak dilakukan penelitian. 


\section{d. Uji Hipotesis}

Pengujian hipotesis dengan uji t digunakan untuk mengetahui hipotesis mana yang diterima. Rumusan hipotesis: Terdapat pengaruh yang signifikan kegiatan promosi terhadap keputusan pembelian.

Tabel 5. Hasil Uji Hipotesis Kegiatan promosi Terhadap Keputusan Pembelian.

$$
\text { Coefficients }^{\mathrm{a}}
$$

Unstandardized

Coefficients

Standardized

Coefficients

\begin{tabular}{|c|c|c|c|c|c|}
\hline Model & B & Std. Error & Beta & $\mathrm{t}$ & Sig. \\
\hline $1 \quad$ (Constant) & 7.748 & 2.411 & & 3.214 & .002 \\
\hline Kegiatan Promosi (X) & .895 & .070 & 790 & 12.774 & .000 \\
\hline
\end{tabular}

a. Dependent Variable: Keputusan Pembelian (Y)

Berdasarkan hasil pengujian pada tabel di atas, diperoleh nilai t hitung $>\mathrm{t}$ tabel atau $(12,774>1,984)$, dengan demikian hipotesis yang diajukan bahwa terdapat pengaruh yang signifikan atara kegiatan promosi terhadap keputusan pembelian diterima.

\section{Pembahasan Hasil Penelitian}

\section{Kondisi Jawaban Responden Variabel Kegiatan Promosi}

Berdasarkan jawaban responden, variabel kegiatan promosi diperoleh ratting score sebesar 3,422 berada di rentang skala 3,40 - 4,19 dengan kriteria baik atau setuju.

\section{Kondisi Jawaban Responden Variabel Keputusan Pembelian}

Berdasarkan jawaban responden, variabel keputusan pembelian diperoleh ratting score sebesar 3,836 berada di rentang skala 3,40 - 4,19 dengan kriteria baik atau setuju.

\section{Pengaruh Kegiatan Promosi Terhadap Keputusan Pembelian}

Kegiatan promosi berpengaruh signifikan terhadap keputusan pembelian dengan persamaan regresi $\mathrm{Y}=7,748+0,895 \mathrm{X}$, nilai korelasi sebesar 0,790 atau memiliki hubungan yang kuat dengan kontribusi pengaruh sebesar 62,5\%. Pengujian hipotesis diperoleh nilai t hitung $>\mathrm{t}$ tabel atau $(12,774>1,984)$. Dengan demikian hipotesis yang diajukan bahwa terdapat berpengaruh signifikan antara kegiatan promosi terhadap keputusan pembelian diterima.

\section{KESIMPULAN DAN SARAN}

\section{Kesimpulan}

a. Variabel kegiatan promosi diperoleh ratting score sebesar 3,422 berada di rentang skala 3,40-4,19 dengan kriteria baik atau setuju.

b. Variabel keputusan pembelian diperoleh ratting score sebesar 3,836 berada di rentang skala 3,40-4,19 dengan kriteria baik atau setuju.

c. Kegiatan promosi berpengaruh signifikan terhadap keputusan pembelian dengan persamaan regresi $\mathrm{Y}=7,748+0,895 \mathrm{X}$, nilai korelasi sebesar 0,790 atau kuat dan kontribusi pengaruh sebesar $62,5 \%$ sedangkan sisanya sebesar $37,5 \%$ dipengaruhi faktor lain. Uji hipotesis diperoleh nilai t hitung > $\mathrm{t}$ tabel atau $(12,774>1,984)$.

\section{Saran}

Berdasarkan hasil penelitian di atas, maka penulis memberikan saran sebagai berikut:

a. PT Manohara Asri disarankan untuk selalu memonitoring kepada salesman dan salesgirl agar terus meningkatkan produk knowledge dan kecakapan dalam 
menjelaskan produk kepada konsumen agar dapat memberikan informasi dengan sangat baik dan mudah dipahami oleh konsumen sehingga dapat meningkatkan minat beli konsumen.

b. Disarankan kepada pihak PT. Manohara Asri harus selalu melakukan riset terusmenerus untuk mengetahui perkembangan dan keinginan serta tingkat kegiatan promosi yang diberikan terhadap konsumen, karena dari hasil penelitian yang telah dilakukan diketahui pengaruh kegiatan promosi terhadap minat beli konsumen.

c. Untuk penelitian selanjutnya, disarankan memasukkan faktor-faktor lain yang mempengaruhi konsumen dalam pengambilan keputusan untuk menjadi konsumen tetap agar hasil penelitian lebih maksimal

\section{DAFTAR PUSTAKA}

Algifari. (2015). Analisis Regresi untuk Bisnis dan Ekonomi. Yogyakarta: BPFE.

Arikunto, Suharsimi (2014). Prosedur Penelitian Suatu Pendekatan Praktek. Jakarta: Rineka Cipta.

Bashu Swastha dan T. Handoko (2015) Manajemen Pemasaran Moderen, Yogyakarta: BPFE.

Basu Swastha Dharmmesta. (2014). Manajemen Pemasaran. BPFE: Yogyakarta. Buchari Alma. 2014. Manajemen Pemasaran dan Pemasaran Jasa. Edisi Revisi.

Bilson Simamora (2016) Panduan Riset Prilaku Konsumen, Jakarta: PT. Gramedia Pustaka.

Fandy Tjiptono (2017), Serivce Quality and Satisfiation. Jakarta: Edisi tiga. Andi.

Freddy Rangkuti (2016) Strategi Promosi Yang Kreatif, Edisi Pertama, Cetakan Pertama Jakarta: Gramedia Pustaka Utama.

Imam Ghozali (2017). Aplikasi Analisis Multivariate Dengan Program SPSS. Edisi Kelima. Semarang: Badan Penerbit Undip.

Istijanto (2014). Riset Sumber Daya Manusia. Jakarta: PT. Gramedia Pustaka

Kharis, Ismu Fadli (2011). Studi Mengenai Impulse Buying dalam Penjualan Online. Semarang : Skripsi Universitas Diponegoro

Kotler dan Amstrong (2017), Prinsip-prinsip Pemasaran. Edisi Kedua Belas”. Jilid Satu. Jakarta: Erlangga.

Lupiyoadi (2016) Manajemen Pemasaran Jasa, Edisi 4, Jakarta: Salemba Empat.

Philip Kotler (2017) Manajemen Pemasaran, Edisi Keempat Belas, Jakarta: PT. Indeks.

Phipil Kotler dan Kevin Keller (2017) Manajemen Pemasaran, Edisi Kedua Belas, Jilid Satu, Jakarta: Erlangga.

Rao, Purba, (2012). Measuring Consumer Perceptions Through Factor Analysis. The Asian.

Santoso, Singgih (2015). Menguasai Statistik Multivariat. Jakarta: PT Elex Media Komputindo.

Sudjana (2014). Metode Statistika, Bandung: Tarsido.

Sugiyono (2017). Metode Penelitian Administrasi : dilengkapi dengan Metode R \& D. Bandung: Alfabeta. 